\title{
Evaluation of Single Unit Blood Transfusion: A Study in Regional Institute of Medical Sciences, Imphal
}

\author{
Dr.Salam Robindro ${ }^{1}$, Dr.K.Rachandra Singh ${ }^{2}$, Dr.L.Dayalaxmi ${ }^{3}$, \\ Dr.Pratima $\mathrm{Kh}^{4}$, Dr.A.Barindra Sharma ${ }^{5}$, Dr.A.Meina $\mathrm{Singh}^{6}$ \\ ${ }^{1}$ Postgraduate trainee, ${ }^{2}$ Assisstant Professor, ${ }^{3}$ Postgraduate trainee, ${ }^{4}$ Senior Resident, ${ }^{5}$ Professor \& Head, ${ }^{6}$ \\ Professor \\ Department of Immunohaematology and Blood Transfusion, Regional Institute of Medical Sciences, \\ Imphal - 795004, Manipur, India
}

\begin{abstract}
Blood transfusion can be a life-saving intervention. However, it may result in acute or delayed complications and carries the risk of transfusion transmissible infections.WHO emphasizes that blood is an expensive and scarce resource; unnecessary transfusions may cause a shortage of blood products for patients in real need besides the risk to the recipient.A reduction in unnecessary transfusions through the appropriate clinical use of blood and blood products and the use of simple alternatives to transfusion wherever possible should be considered. Avoidance of single unit red cell transfusion is also one of the measures of rational use of blood. Some guidelines prefer single unit transfusion for it may reduce transfusion associated and dosedependant morbidity and mortality. We follow that blood transfusion is indicated when haemoglobin $(\mathrm{Hb})$ level is $<7 \mathrm{gm} \%$, to consider transfusion when $\mathrm{Hb}$ is $7-10 \mathrm{gm} \%$ if associated with symptoms or cardio-respiratory insufficiency and no transfusion when $\mathrm{Hb}$ is $>10 \mathrm{gm} \%$ in a non-bleeding patient. During the study period of two years from January 2014 to December 2015 in Regional Institute of Medical Sciences, Imphal, single red cell units constituted 2232 out of 22546 total red cell units issued(9.9\%).Based on our protocol, 480 single unit transfusions out of 2232 units were unjustified and in our context of limited resources, more demand and less supply. Group discussions and awareness sessions with clinicians will be of immense help towards rational use of blood. The study is being presented.
\end{abstract}

Keywords: Haemoglobin level, ratinal use of blood, red cell transfusion, single unit blood, transfusion transmissible infections

\section{Introduction}

Blood transfusion is a life-saving intervention. However, it always carries potential risks for the recipient like transfusion related adverse reactions, transfusion transmissible infections, alloimmunization etc. Blood is an expensive and scarce resource. Therefore, unnecessary transfusions may cause a shortage for those patients who are in real need and also exposure to unnecessary risks for the recipients.Blood transfusion should be prescribed only when benefits are likely to outweigh the risks.[1].For many decades the decision to transfuse red blood cells was based upon the "10/30"; transfusion was used to maintain a blood haemoglobin concentration above $10 \mathrm{~g} / \mathrm{dl}$ and a haematocrit above $30 \%$ [2]. Later,a large body of clinical evidence was generated resulting in the publication of many guidelines for red blood transfusion in different settings. [3,4].A common theme of these guidelines is the need to balance the benefit of treating anaemia with the desire to avoid unnecessary transfusion with its associated costs and potential harms. Avoidance of single unit transfusion is one of the measures of rational use of blood. The objective of the study is to know the incidence and pattern of single unit blood transfusion in Regional Institute of Medical Sciences, Imphal.

\section{Materials And Methods}

The period of study was from January 2014 to Dec 2015 (24 months).Scrutiny of blood transfusion request forms received in the Department of Immonohaematology and Blood Transfusion, Regional Institute of Medical Sciences, Imphal was done and the details of the patients regarding clinical diagnosis, age, sex, haemoglobin $(\mathrm{Hb})$ value, indication of transfusion and blood/ component ordered were recorded.Blood unit issued was also noted.Only Packed $\mathrm{RBC} /$ Whole blood(WB) units issued and utilised were taken into account.Single blood unit transfusions were selected and recorded for analysis.Congenital anaemia cases e.g. Thalassaemia, Sickle cell anaemia etc. were excluded because of single unit transfusion at regular intervals.

\section{Results}

A total of 22546 PRBC/WB units were issued from Jan 2014 to Dec 2015, out of which single unit transfusion constituted 2232units (9.9\%). Male to Female sex ratio was 1:2.04. Age range varied from 18 days 
to 83 years. Out of 2232 single unit transfusions, $1480(66.3 \%)$ had $\mathrm{Hb}$ value between 7 to $10 \mathrm{gm} / \mathrm{dl}, 177(7.9 \%)$ had above $10 \mathrm{gm} / \mathrm{dl}$ and 575 ( $25.7 \%$ ) had below $7 \mathrm{gm} / \mathrm{dlHb}$. The major single unit transfusion took place in Obstetrics\&Gynaecology Department comprising 938 out of 2232 ( 42.03\%) followed by Medicine Department comprising 281 out of 2232 ( $12.60 \%$ ) and the least was in Urology department(0.72\%). (TABLE 1).

Table 1.Department wise distribution of single unit blood transfusion.

\begin{tabular}{|l|l|l|l|}
\hline Sl. No & Name of the Department & No. of single unit transfusion & Percentage (\%) \\
\hline 1 & Obstetrics \& Gynaecology & 938 & 42.03 \\
\hline 2 & Medicine & 281 & 12.60 \\
\hline 3 & Radiotherapy & 276 & 12.37 \\
\hline 4 & Casualty & 202 & 9.04 \\
\hline 5 & Surgery & 140 & 6.25 \\
\hline 6 & Nephrology & 122 & 5.47 \\
\hline 7 & Orthopaedics & 69 & 3.10 \\
\hline 8 & Paediatrics & 69 & 3.10 \\
\hline 9 & Respiratory Medicine & 48 & 2.15 \\
\hline 10 & CTVS & 27 & 1.19 \\
\hline 11 & Otorhinolaryngology & 24 & 1.08 \\
\hline 12 & Plastic surgery & 20 & 0.90 \\
\hline 13 & Urology & 16 & 0.72 \\
\hline
\end{tabular}

CTVS: Cardiothoracic and Vascular Surgery

\section{Discussion}

According to WHO guidelines,blood transfusion should be prescribed only for conditions with significant potential for morbidity or mortality that cannot be prevented or managed effectively by other means. Careful assessment of clinical and laboratory indications are necessary. Haemoglobin value although important, should not be the sole deciding factor for blood transfusion, particularly in blood loss.[1]. There is general agreement that RBC transfusion is indicated if $\mathrm{Hb}$ level is $<7$ to $8 \mathrm{gm} / \mathrm{dl}$ and not indicated when $\mathrm{Hb}$ levels of $>$ $10 \mathrm{gm} / \mathrm{dl}$ in stable ,nonbleeding medical and surgical inpatients.[5,6].RBC transfusion is indicated in patients who are actively bleeding and should be based on clinical assessment in addition to laboratory testing. A recent study examining transfusion in patients with active gastrointestinal bleeding showed superior outcomes in patients with a restrictive transfusion $(\mathrm{Hb}<7 \mathrm{gm} / \mathrm{dl})$.[7]. In our hospital we also recommend $\mathrm{RBC}$ transfusion when $\mathrm{Hb}$ is $<7 \mathrm{gm} / \mathrm{dl}$; to consider transfusion when $\mathrm{Hb}$ is between $7-10 \mathrm{gm} / \mathrm{dl}$ if associated with symptoms or cardio-respiratory insufficiency and no transfusion when $\mathrm{Hb}$ is $>10 \mathrm{gm} / \mathrm{dl}$ in non- bleeding patient. One unit of $\mathrm{PRBC} /$ whole blood would raise approximately $1 \mathrm{gm} / \mathrm{dl}$ of $\mathrm{Hb}$ which is therapeutically insignificant.[8].

In our study, we have felt that patients with $\mathrm{Hb}>7$ to $10 \mathrm{gm} / \mathrm{dl}$, single unit transfusion could have been avoided in good number of cases with the use of other safer alternatives. Patients with $\mathrm{Hb}>10 \mathrm{gm} / \mathrm{dl}$, blood transfusion was not justified.Based on these criteria and the available clinical details ,480 single unit transfusions out of 2232 units were unjustified (21.5\%).Majority of the patients were labelled as full term pregnancy with anticipated bleeding, chronic anaemia, anaemia under evaluation, alcoholic liver disease with anaemia, diabetes mellitus with hypertension, preoperative with anticipated bleeding etc. which are not valid reasons for transfusion.

Some guidelines recommend single unit transfusion with the reasons that it reduces the patient's exposure to allogenic blood with more than one unit transfusion and possibility of dose-dependent increased risk of nosocomial infection and other morbidities. They also recommend to transfuse one unit at a time and only when clinically indicated, based on the need to relieve clinical signs and symtoms of anaemia. If one unit has achieved the stated outcome for the red cell transfusion, further units will only increase the risks. $(9,10,11)$.In our context of more demand, less supply and limited resources, we advocate restriction of single unit transfusion unless indicated.

In a study by Vachhani $\mathrm{JH}$ et al, single unit transfusion constituted $55.1 \%$ of all transfusions. After having group discussions and awareness sessions with clinicians, the single unit transfusions came down to 52.81\%.[12].In other studies the percentage of single unit transfusion were 38.9\%[13] and 21.6\%,[14] respectively. In our study the percentage of $9.9 \%$ is comparatively lower. WHO advocates that the need of transfusion can be avoided by prevention or early diagnosis and treatment of anaemia,correction of anaemia and replacement of depleted iron stores before planned surgery and use of simple alternatives to transfusion like intravenous replacement fluids, good anaesthetic and surgical management.Blood should not be given for volume expansion , as haematinic / tonic, to enhance wound healing or to improve general well-being. If given when it is not needed, the patient receives no benefit and is exposed to unnecessary risk.(1). 


\section{Conclusion}

We support reduction in unnecessary blood transfusions through the appropriate clinical use of blood and blood products and avoidance of single unit transfusion in our context of limited resources, more demand and less supply. Group discussions and awareness sessions with the blood user depatments will be of immense help in this direction.

\section{References}

[1] The Clinical use of Blood. Blood Transfusion Safety .World Health Organization, Geneva, 2002.

[2] Wang JK, Klein HG.Red blood cell transfusion in the treatment and management of anaemia: the search for the elusive transfusion trigger. Vox Sang, 98(1), 2010, 2-11

[3] Practice Guidelines for blood component therapy.A report by the American Society of Anaesthesiologists Task force of Blood Component therapy. Anaesthesiology, 84, 1996, 732

[4] Napolitano LM, Kurek S, Luchette FA et al. Clinical practice guidelines: red blood cell transfusion in adult trauma and critical care. Crit Care Med, 37, 2009,3124

[5] Szczepiorkowski ZM, AuBuchan JP. The role of physicians in hospital transfusion services.Transfusion, 45(5), 2006, 862-867

[6] Murphy MF, Wallington TB, Kelsey P et al. Guidelines for the clinical use of red cell transfusions. BrJ Haematol, 113(1), 2001, 2431

[7] Villanueva C, Colomo A, Bosch A et al. Transfusion strategies for acute upper gastrointestinal bleeding. $N$ Engl $J$ Med, 368(1), 2013, 11-21

[8] Kennedy MS, Wu HM. Transfusion therapy and Transfusion in Transfusion. In D.M.Harmening(Ed.),Modern Blood Banking \& Transfusion Practices.(New Delhi, Jaypee Brothers Medical Publishers, $5^{\text {th }}$ edn., 2008), 303-354

[9] Ma M, Eckert K, Ralley F, Chin-Yee I. A retrospective study evaluating single-unit red blood cell transfusions in reducing allogeneic blood exposure.Transfusion Medicine, 15,2005, 307-312

[10] Hajjar LA, Vincent JL et al.Transfusion requirements after cardiac surgery; the TRACS randomised controlled trial. $J A M$, 304(14), 2010, 1559-1567.

[11] Single unit Transfusion Guide. National Blood Authority, Australia, Canberra, June 2014

[12] Vachhani JH, Joshi JR, Bhanvandia VM. Rational use of blood: a study report on single unit transfusion, Indian J Haematol Blood Transfus, 24(2), 2008, 69- 71.

[13] Gupte SC, Shaw A. Evaluation of single unit red cell transfusions given to adults during surgery. Asian J TransfusSci, 1,2007, 1215

[14] Venkatachalapathy TS. A prospective Audit of Blood Transfusion Reactions in Tertiary Care Hospital for the Use of Blood and Blood Components. J Blood DisordTransfus , 3, 2012 ,118. Doi:10.4172/2155-9864.1000118. 